\title{
Acute effect of low and moderate glycemic index drinks on plasma glucose level in professional football players during prolonged intermittent exercise
}

\author{
Zane Andersone' ${ }^{1}$ Lìga Ozolina-Moll2* \\ ${ }^{1}$ Department of Sports and Nutrition, Riga Stradins University, Anninmuizas 26A, Riga LV-1067, Latvia \\ ${ }^{2}$ Department of Human and Animal Biology, Faculty of Biology, University of Latvia, Jelgavas 1, Riga LV-1004, Latvia \\ ${ }^{\star}$ Corresponding author, E-mail: ligaozol@lu.lv
}

\begin{abstract}
Carbohydrate is the main fuel for muscles during exercise and depletion of glycogen stores has been associated with the onset of fatigue. However, scientific evidence of the importance of carbohydrate in energy supply in athletes is still conflicting. The aim of the study was to evaluate changes of the plasma glucose in professional athletes - football players - during prolonged exercise after intake of drinks with different glycemic index (GI). In total, 24 athletes participated in the study. During two 90-min exercise sessions of football training games, the plasma glucose level was measured every $15 \mathrm{~min}$. In the first session changes of plasma glucose level were measured after consumption of a low GI drink, and in the second session after consumption of a moderate GI drink. The results of the study indicated that plasma glucose level did not differ significantly over a 90 min intermittent exercise after ingestion of moderate and low GI drinks.
\end{abstract}

Key words: football players, glycemic index, intermittent exercise, plasma glucose.

Abbreviations: GI, glycemic index.

\section{Introduction}

Football, as well as field hockey, handball, basketball, rugby and racquet sports, are characterised as intermittent sports because of their demands of high-intensity play interspersed with periods of submaximal effort over a long period, using both aerobic and anaerobic energy systems, relying on muscle glycogen and/or blood glucose as an important substrate for energy recovery (Bangsbo 1994; Mujika, Burke 2010; Holway, Spriet 2011; Baker et al. 2015). Therefore, athletes must have developed ability to perform high intensity activities such as sprint, as well as ability to replenish capacity to work during low intensity activities such as walking or jogging over a long period of time.

The importance of carbohydrate intake in intermittent sport achievement is dependent on the status of carbohydrates in an athlete's plasma and its regulation in the body as well as its availability to the skeletal muscles. Therefore, very often athletes consume carbohydrates in the form of a drink with moderate or high glycemic index (GI). These products quickly enter blood circulation from the digestive system and subsequently the carbohydrates are used in the muscles. This allows for quick use of consumed carbohydrates and possibly even the development of hypoglycaemia. Specifically, the intake of carbohydrates before and during games has significant effect on an athlete's performance until the end of the game, especially in such sports where high performance must be maintained for several hours.

Carbohydrates are the main source of energy for working muscles and can provide long-lasting, but also fast energy supply; depletion of carbohydrate stores has been associated with fatigue (Ørtenbland et al. 2013; Wan et al. 2017). However, fatigue is difficult to assess during an actual game because each of the players shows different work intensity. Scientific literature provides much data on the effects of high GI food/drink intake on the dynamics of plasma glucose, but effect of moderate GI dietary intake to athletes' performance has not been frequently studied. Current guidelines for athletes competing in intermittent sports recommend ingesting carbohydrate at a rate of 30 to $60 \mathrm{~g} \mathrm{~h}^{-1}$ during $>1 \mathrm{~h}$ of training and competition (Rodriguez et al. 2009; Mujika, Burke 2010; Burke et al. 2011; Holway, Spriet 2011; Baker et al. 2015).

Although a carbohydrate-rich diet is the main source of nutrition to intermittent sports athletes, scientific knowledge about the importance of GI and the composition of carbohydrates are controversial. It was established in studies that intake of food / drink with high GI 30 to $60 \mathrm{~min}$ and up to $3 \mathrm{~h}$ before high intensity exercise leads to faster and premature fatigue when compared to products with low GI. This is associated with a fast decrease of glucose level as well as the use of fatty acids in the beginning of exercise (Little et al. 2009; Little et al. 2010). Nevertheless, 
conclusions of opposite opinion have also been made. For example, intake of food with low and high GI before exercise was not observed to lead to differences between these two groups in the times of reaching exhaustion nor in the performance of the athletes (Jamurtas et al. 2011).

The aim of the current study was to evaluate the dynamics of the plasma glucose level in professional athletes - football players, during prolonged exercise after intake of drinks with different (low and moderate) glycemic index.

\section{Materials and methods}

\section{Participants}

Twenty four professional male football players with age $22.0 \pm 2.6$ years participated in the study. The athletes have been professionally trained in football for more than 10 years, five to seven times per week. The measurements were performed at least 3 to $4 \mathrm{~h}$ after meals during which only drinking of water was allowed. Body weight and height were measured during the mandatory health examination in the laboratory of Latvian Olympic Unit. The average weight of study participants was $77.1 \pm 8.7 \mathrm{~kg}$, average height $183.4 \pm$ $7.5 \mathrm{~cm}$, body mass index $22.9 \pm 1.6 \mathrm{~kg} \mathrm{~m}^{-2}$.

The study was approved by the Ethics Committee of Riga Stradiņš University.

\section{Procedure}

Plasma glucose level was measured using an Accu Chek Active glucometer (Roche). There were two exercise sessions: football training games of $90 \mathrm{~min}$ duration. Every 15 min capillary blood samples were taken from each participant. In the first session changes of glucose level were measured after consumption of a low GI drink (GI $53 \pm 6$ ), and in the second session after consumption of moderate GI drink (GI $68 \pm 6$ ). In order for athletes to obtain an equivalent amount of energy (calories) in both sessions these drinks were taken in different volumes: the drink with low GI was $200 \mathrm{~mL}$ orange juice and the drink with moderate GI was $167 \mathrm{~mL}$ of non-alcoholic soft drink with orange taste. GI of drinks was determined from data available in scientific literature (Atkinson et al. 2008).

The first plasma glucose measurement was performed just before consumption of the drink, 30 min before the start of the football training game. Subsequent measurements were performed after ingestion of drinks just before the training game (indicated further as the 0 minute) and every 15 min during the training session: in $15^{\text {th }}, 30^{\text {th }}, 45^{\text {th }}, 60^{\text {th }}$, $75^{\text {th }}, 90^{\text {th }}$ minute.

The study was performed during the practice at a football field.

\section{Data analysis}

For data processing the computer program SPSS 20.0 and statistics standby program were used. Descriptive and comparative statistics data analysis methods were performed in the study. The Shapiro-Wilk test was used to test normality. Statistical difference between measurements was determined by a Paired Samples $t$ Test. A $p$ value $<0.05$ was considered as statistically significant. All data in figures are presented as mean values \pm standard deviation.

\section{Results}

\section{Plasma glucose changes after low glycemic index drink consumption}

Plasma glucose concentration was determined for all participants $(n=24)$ and all collected data were valid and processed. The average plasma glucose concentration before drink consumption among study participants was $5.1 \pm 0.4 \mathrm{mmol} \mathrm{L}^{-1}$, with minimum value $4.5 \mathrm{mmol} \mathrm{L}^{-1}$ and maximum value $6.0 \mathrm{mmol} \mathrm{L}^{-1}$.

During exercise, changes in plasma glucose concentration showed a variable trend (Fig. 1). A moderate, but not statistically significant decrease in plasma glucose concentration occurred in the first half of the exercise session, with initial value $5.3 \pm 0.5 \mathrm{mmol} \mathrm{L}^{-1}$ and lowest level $\left(4.5 \pm 0.5 \mathrm{mmol} \mathrm{L}^{-1}\right)$ at about $30^{\text {th }}$ and $45^{\text {th }}$ min of the session. In the second half of the exercise session plasma glucose level showed a tendency

\section{Plasma glucose changes after moderate glycemic index drink consumption}

As in the first training session, plasma glucose level was determined for all football players before moderate glycemic index drink consumption with an average value $5.0 \pm 0.3$ mmol L ${ }^{-1}$. This value showed no statistically significant difference with plasma glucose concentration before the first exercise session. The first measurement of plasma glucose concentration after consumption of a moderate glycemic index drink, made just before the exercise session, showed average plasma glucose level $5.2 \pm 0.3 \mathrm{mmol} \mathrm{L}^{-1}$.

Also in the second exercise session, changes in plasma glucose concentration after moderate GI drink consumption showed a variable pattern, although plasma glucose concentrations did not show statistically significant differences between times of glucose measurements. Glucose measurements in this exercise session showed greater inter-individual variation of results among the subjects.

Plasma glucose concentration after 15 min of exercise showed the same mean value as at the beginning of exercise session $\left(5.2 \pm 0.6 \mathrm{mmol} \mathrm{L}^{-1}\right)$, but in this case there was a higher standard deviation, and three replicates estimated from the sample (measurement values 3.5, 4.2 and $4.3 \mathrm{mmol}$ $\mathrm{L}^{-1}$ ) significantly differed (Fig. 2) reaching a coefficient of variation $>5 \%$. Also the statistical median value of the $1^{\text {st }}$ and $2^{\text {nd }}$ measurements of the exercise session (at the beginning of session and at the $15^{\text {th }} \mathrm{min}$, respectively) differed: 5.2 and $5.4 \mathrm{mmol} \mathrm{L}^{-1}$, respectively.

Likewise, in the first exercise session the lowest plasma 


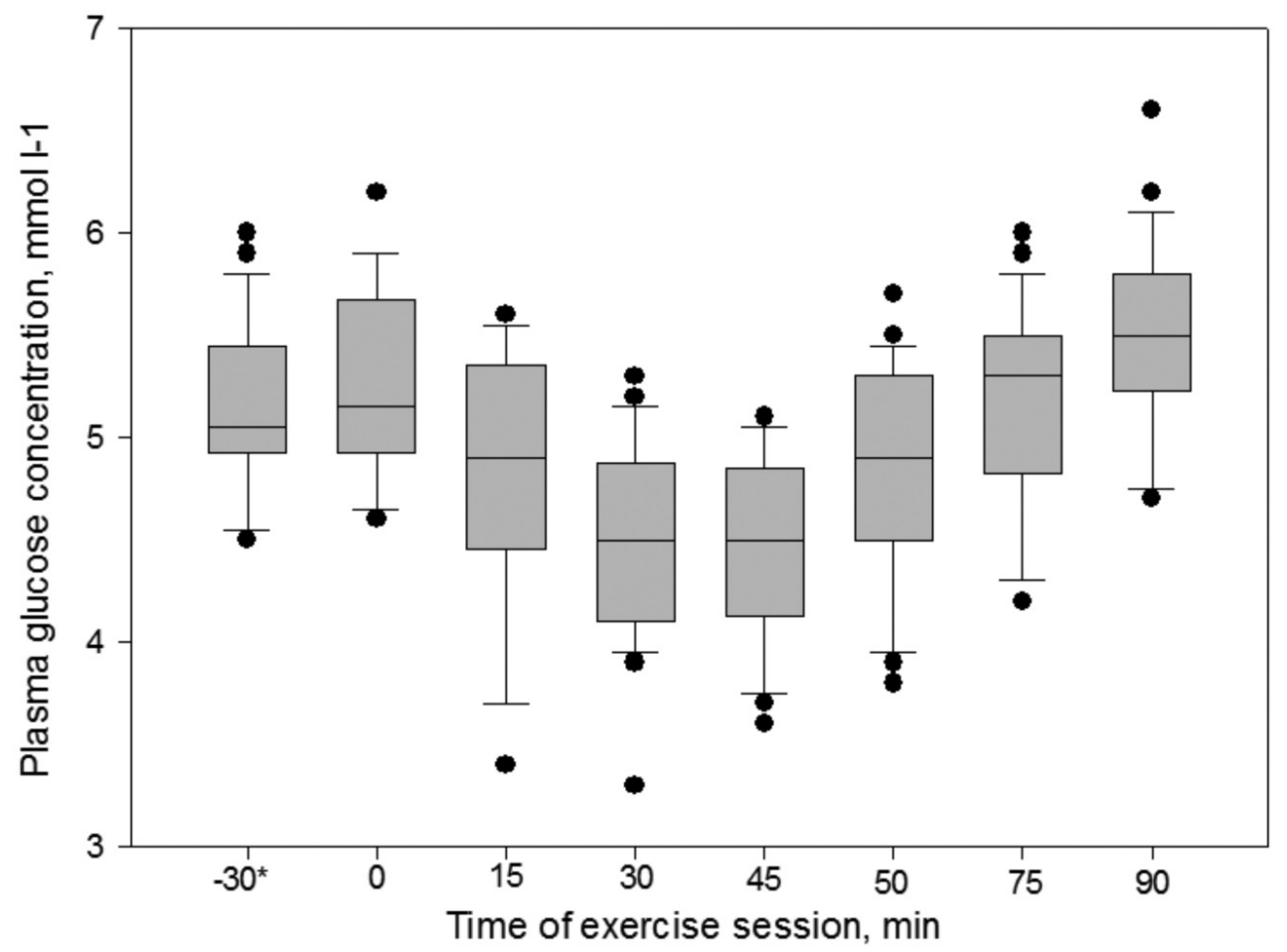

Fig. 1. Plasma glucoses trend after consumption of a low glycemic index drink. ${ }^{*}$ indicates time 30 min before exercise session, just before consumption of a low glycemic index drink.

glucose concentration level was observed during the football session between the $30^{\text {th }}$ to $45^{\text {th }}$ min, when mean plasma glucose concentration dropped to $4.5 \pm 0.6$ and 4.5 $\pm 0.5 \mathrm{~L}^{-1}$, and later increased to $5.8 \pm 0.4 \mathrm{mmol} \mathrm{L}^{-1}$ in the $90^{\text {th }}$ min of the exercise (Fig. 2).

\section{Comparative evaluation of plasma glucoses changes after low and moderate glycemic index drink consumption}

Comparing the trend of plasma concentration, a similar pattern of glucose level changes after consumption of low and moderate GI drinks was found. At the beginning of the exercise sessions, glucose concentration decreased, reaching the lowest level in the middle part of the exercise sessions at about 30 to $45 \mathrm{~min}$, followed by plasma glucose mobilization and an increase in its concentration at the end of the exercise.

Comparing the plasma glucose change dynamics during a 90 min period between the football training sessions, there was no statistically significant difference $(p>$ 0.05 ) between mean plasma glucose concentration at every 15 min. However, plasma glucose concentration showed a tendency for higher, but not statistically significant, glucose level after ingestion of moderate GI drink and the most obvious difference in glucose concentration appeared at the $15^{\text {th }}$ min of the exercise sessions, when this difference was $0.4 \mathrm{mmol} \mathrm{L}^{-1}$.

Although plasma glucose concentration changes during exercise sessions were statistically non-significant ( $p$ value in all cases was greater than 0.05 ), these changes and the availability of glucose as an energy substrate for working muscle can influence physical performance of athletes during the sport game.

\section{Discussion}

The majority of studies show that intake of carbohydrates by intermittent exercise athletes before exercise increases exercise capacity. However, the studies show different results regarding acute effect of carbohydrate intake for athletes of intermittent sports that require various qualities such as dash, jumping, abrupt change of running direction, and cognitive capabilities. Consumption of carbohydraterich drinks, which is often combined with electrolytes and/ or stimulants of the nervous system, are used to postpone fatigue. It must be noted that there can be many different causes of fatigue and deterioration in sports performance, for example deviations of homeostasis of electrolytes such as sodium, potassium, and chlorine in skeletal muscle during exercise, or an intramuscular accumulation of hydrogen ions and inorganic phosphate (More et al. 2005; Bangsbo et al. 2006), low muscle glycogen (Krustrup et al. 2006), decreased plasma glucose level and its accessibility/ transportation from plasma to the working tissue, as well as different work intensity of players, which is difficult to assess during an actual game.

The results of our study showed similar plasma glucose level change dynamics during a prolonged exercise in both sessions and for both - moderate and low GI drink 


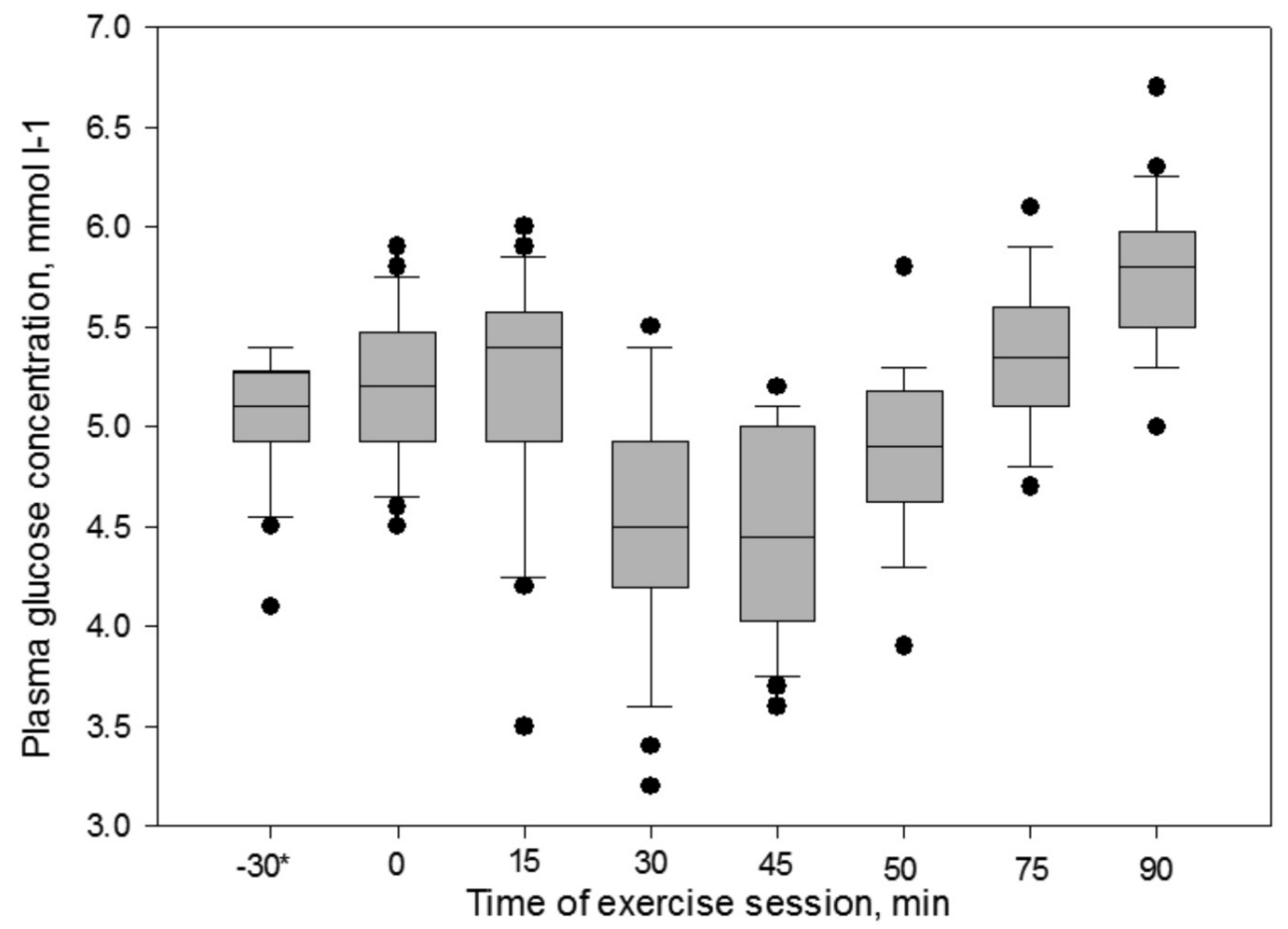

Fig. 2. Plasma glucoses trend after consumption of a moderate glycemic index drink. ${ }^{\star}$ indicates time 30 min before exercise session, just before consumption of a moderate glycemic index drink.

- intake. Glucose plasma concentration decreased during the first $60 \mathrm{~min}$ of intermittent exercise followed by an increase of glucose level until the end of exercise $\left(90^{\text {th }} \mathrm{min}\right)$. During exercise, muscular contraction causes an increased uptake of glucose from the blood, explaining the decrease in glucose level observed during the 1st hour. Because in our study no other parameters related to sugar regulation in plasma and its uptake in muscles were estimated, only speculation about the causes for increase of the plasma glucose level during the final period of the exercise can be made, and it is very likely that such increase could be observed also during recovery period.

It is long known that plasma glucose concentration can increase in response to intermittent sport activity due to an increase in circulating catecholamine (Bangsbo 1994; Jacob et al. 2004; Zouhal et al. 2008; Thomas at al. 2016) due to stimulation of the sympathetic nervous system. Glycogenolysis in liver is stimulated by catecholamine, which results in an elevated plasma glucose level even exceeding resting values (Zouhal et al. 2008). A similar, temporary decline in plasma glucose level and even hypoglycaemia has been observed in football players during the first half-time in studies by other authors (Russell et al. 2011; Russell et al. 2010; Kingsley et al. 2014). This suggests that liver glycogen is sufficient to maintain plasma glucose level during a football game and even during the overtime period (Harper et al 2016). This is also one of the reasons why consumption of carbohydrate-rich drinks is not advised for team sport athletes during game/exercise, to maintain endogenous regulation of glycogen homeostasis and produce high performance of athletes even during the final stages of a prolonged exercise.

According to our research data, plasma glucose level was higher, but not significantly, after moderate GI drink intake during the beginning of exercise session (at about $15^{\text {th }}$ $\min$ ) and during the final phase of the exercise (after $75^{\text {th }}$ minute). In the phase of exercise when the lowest glucose level was observed, significant difference in plasma glucose concentration between the two sessions was not observed. The small, but not significant difference in glucose level between the study sessions was not surprising because immediate, rather high influx of glucose into circulation from the digestive tract is characteristic for consumption of drink/food with high GI, as opposed to consumption of low GI food/drink, which results in a relatively slow transfer of sugars to blood.

Contrary to expectation, following a decline in plasma glucose a small, but not statistically significant increase of glucose level was observed during the final phase of exercise. To determine whether this difference is systematic and to identifye the underlying reasons, further studies are required.

Our study did not show statistically significant differences in the plasma glucose trends over a $90 \mathrm{~min}$ intermittent exercise after ingestion of low and moderate glycemic index drinks. However, the average glucose concentration after moderate GI drink consumption had greater inter-individual variation, which could significantly influence the overall team performance in team sports. 


\section{References}

Atkinson F.S., Foster-Powell K., Brand-Miller J. C. 2008. International tables of glycemic index and glycemic load values: 2008. Diab. Care 31: 2281-2283.

Baker L.B., Rollo I., Stein K.W., Jeukendrup A.E. 2015. Acute effects of carbohydrate supplementation on intermittent sports performance. Nutrients 7: 5733-5763.

Bangsbo J. 1994. The physiology of soccer - with special reference to intensive intermittent exercise. Acta Physiol. Scand. 151: $1-15$.

Bangsbo J., Mohr M., Krustrup P. 2006. Physical and metabolic demands of training and match-play in the elite football player. J. Sports Sci. 24: 665-674.

Burke L.M., Hawley J.A., Wong S.H., Jeukendrup A.E. 2011. Carbohydrates for training and competition. J. Sports Sci. 29: 17-27.

Harper L.D., Briggs M.A., McNamee G., West D.J., Kilduff L.P., Stevenson E., Russell M. 2016. Physiological and performance effects of carbohydrate gels consumed prior to the extra-time period of prolonged simulated soccer match-play. J. Sci. Med. Sport. 19: 509-514.

Holway F.E., Spriet L.L. 2011. Sport-specific nutrition: Practical strategies for team sports. J. Sports Sci. 29: 115-125.

Jacob C., Zouhal H., Prioux J., Gratas-Delamarche A., BentueFerrer D., Delamarche P. 2004. Effect of the intensity of training on catecholamine responses to supramaximal exercise in endurance-trained men. Eur. J. Appl. Physiol. 91: 34-40.

Jamurtas A.Z., Tofas T., Fatouros I., Nikolaidis M.G., Paschalis V., Yfanti C., Raptis S., Koutedakis Y. 2011. The effects of low and high glycemic index foods on exercise performance and betaendorphin responses. J. Int. Soc. Sports Nutr. 20: 8-15.

Kingsley M., Penas-Ruiz C., Terry C., Russell M. 2014. Effects of carbohydrate-hydration strategies on glucose metabolism, sprint performance and hydration during a soccer match simulation in recreational players. J. Sci. Med. Sport. 17: 239243.
Krustrup P., Mohr M., Steensberg A., Bencke J., Kjaer M., Bangsbo J. 2006. Muscle and blood metabolites during a soccer game: Implications for sprint performance. Med. Sci. Sports Exerc. 38: 1165-1174.

Little J., Chilibeck P., Ciona D., Vandenberg A., Zello G. 2009. The effects of low- and high-glycemic index foods on highintensity intermittent exercise. Int. J. Sports Physiol. Perform. 4: $367-380$.

Little J., Chilibeck P., Ciona D., Forbes S., Rees H., Vandenberg A., Zello G. 2010. Effect of low- and high-glycemic-index meals on metabolism and performance during high-intensity, intermittent exercise. Int. J. Sport Nutr. Exerc. Metab. 20: 447456.

Mohr M.; Krustrup P.; Bangsbo J. 2005. Fatigue in soccer: A brief review. J. Sports Sci. 23: 593-599.

Mujika I.; Burke L.M. 2010. Nutrition in team sports. Ann. Nutr. Metab. 57: 26-35.

Ørtenblad N., Westerblad H., Nielsen,J. 2013. Muscle glycogen stores and fatigue. J. Physiol. 591: 4405-4413.

Rodriguez N.R., DiMarco N.M., Langley S. 2009. Joint position of the American Dietetic Association, Dietitians of Canada, and the American College of Sports Medicine: Nutrition and athletic performance. J. Am. Diet Assoc. 109: 509-527.

Russell M., Benton D., Kingsley M. 2012. Influence of carbohydrate supplementation on skill performance during a soccer match simulation. J. Sci. Med. Sport. 15: 348-354.

Russell M., Rees G., Benton D., Kingsley M. 2011. An exercise protocol that replicates soccer match-play. Int. J. Sports Med. 32: 511-518.

Thomas F., Pretty, C.G., Desaive T., Chase J.G. 2016. Blood glucose levels of subelite athletes during 6 days of free living. J. Diab. Sci. Technol. 10: 1335-1343.

Wan J., Qin Z., Wang P., Sun Y., Liu X. 2017. Muscle fatigue: general understanding and treatment. Exp. Mol. Med. 49: e384.

Zouhal H., Jacob C., Delamarche P., Gratas-Delamarche A. 2008. Catecholamines and the effects of exercise, training and gender. Sports Med. 38: 401-423. 